\title{
Documentation and virtual reconstruction of historical objects in Peru damaged by an earthquake and climatic events
}

\author{
K. Hanzalová and K. Pavelka \\ Czech Technical University in Prague, Thákurova 7, 16609, Prague 6, Czech Republic \\ Correspondence to: K. Pavelka (pavelka@fsv.cvut.cz) \\ Received: 6 February 2013 - Revised: 31 May 2013 - Accepted: 3 June 2013 - Published: 3 July 2013
}

\begin{abstract}
This paper deals with the possibilities of creating a 3-D model and a visualization technique for a presentation of historical buildings and sites in Peru. The project Nasca/CTU is documenting historical objects by using several techniques. This paper describes the documentation and the visualization of two historical churches (San Jose and San Xavier Churches) and the pre-Hispanic archaeological site La Ciudad Perdida de Huayuri (Abandoned town near Huayuri) in Nasca region by using photogrammetry and remote sensing. Both churches were damaged by an earthquake. We use different process for the documentation of these objects. Firstly, PhotoModeler software was used for the photogrammetric data processing of the acquired images. The subsequent making models of both churches were different too. Google SketchUp software was used for the San Jose Church and the 3-D model of San Xavier Church was created in MicroStation software. While in the modelling of the "Abandoned town" near Huayuri, which was destroyed by a climatic event (El Niño), the terrestrial photogrammetry, satellite data and GNSS measurement were applied. The general output of the project is a thematic map of this archaeological site; $\mathrm{C}^{14}$ method was used for dating.
\end{abstract}

\section{Introduction}

Around Nasca and Palpa city in Peru there are many interesting historical objects which are suitable for documentation (Eisenbeis et al., 2005). In HTW Dresden (University of Applied Sciences, Germany) the project Nasca was started in 1995 (Richter, 2007). The main goal was to prolong the scientific work of Dr. Maria Reiche which focused on the documentation and investigation of geoglyphs in the Nasca region and preservation of other cultural heritage in digital form
(Musílek et al., 2001). For that reason, a NascaGIS application was developed. The primary requirement of any GIS application is the data. The photogrammetric approach is one of the most practical solutions to capture such data. Not only geoglyphs, but all valuable historical objects are documented, such as buildings, petroglyphs and selected archaeological sites. The Nasca/CTU project has cooperated with the Nasca project in HTW Dresden since 2004. Within the project, four German-Czech expeditions to Peru have been performed focusing on Nasca region and other areas. The famous Nasca Lines are the core of the Nasca project. We concentrated on other lesser-known objects of interest - endangered monuments like churches or archaeological sites, frequently prone to destruction. San Jose Church, San Xavier Church, hacienda de La Peňa or the archaeological site "Abandoned town near Huayuri" can be mentioned. Some of these objects were destroyed by an earthquake (churches), while others, mainly archaeological sites, were destroyed by climatic events (El Niño). Data of historical objects or sites was acquired for the documentation process during the expeditions to Peru in 2008, 2010 and 2012. This paper deals with three of them: San Jose and San Xavier Churches and an abandoned town near Huayuri. These three objects are historically interesting and adequate from our point of view as well as they are suitable for our technological possibilities in Nasca region.

\section{Objects of interest}

San Jose Church is situated in the El Ingenio region approximately $30 \mathrm{~km}$ northwest of Nasca City $\left(\varphi=14^{\circ} 40^{\prime} 15^{\prime \prime} \mathrm{S}\right.$, $\lambda=75^{\circ} 07^{\prime} 44^{\prime \prime} \mathrm{W}$, Fig. 1). The church was built in 1744 in the baroque style. There are two wooden towers covered by plaster, which dominates the church. Twelve crypts were 

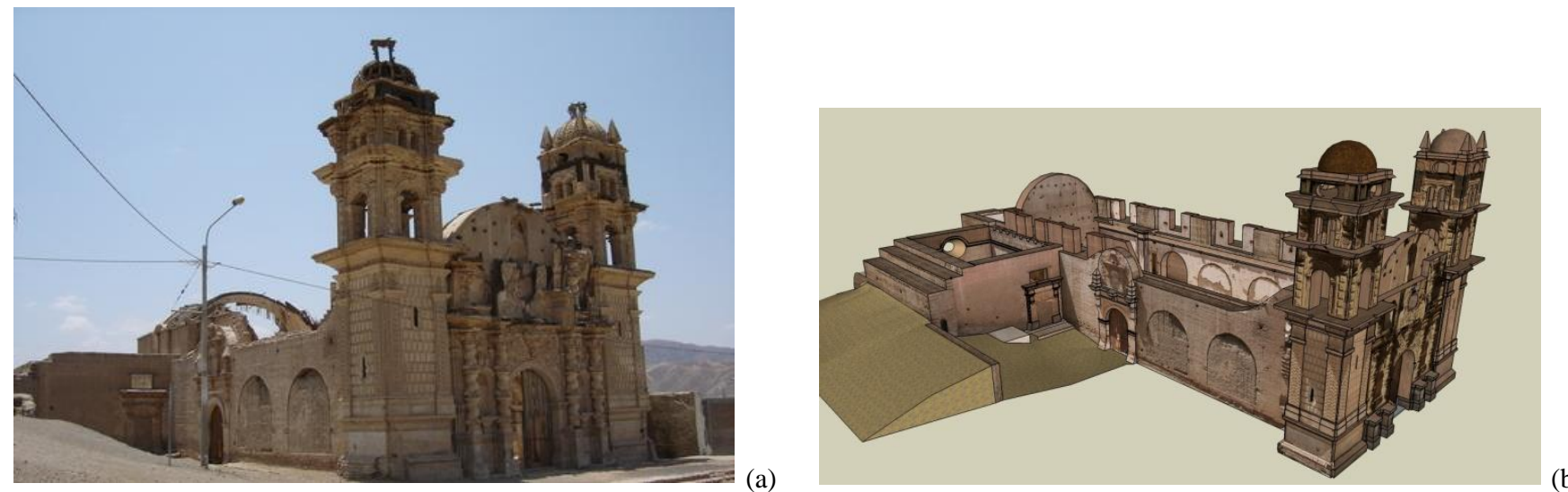

(b)

Fig. 1. Original image of San Jose Church (a). Images taken by calibrated camera were used for creating of the 3-D model for Google Earth (b; Hanzalová and Čumpelík, 2011).
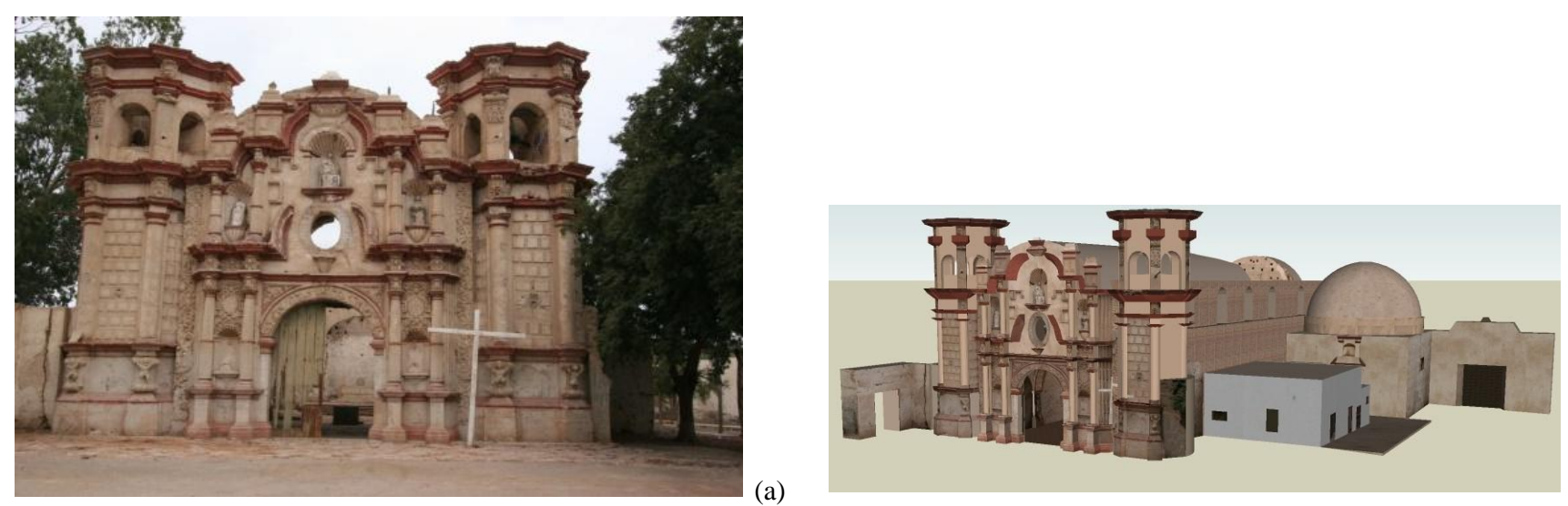

(b)

Fig. 2. San Javier Church and 3-D model (a) (b; Kostka and Pavelka, 2011).

found under the church. Documentation work was conducted in 2010. The second object, San Javier Church is a typical object, which represents some of the most outstanding examples of baroque architecture in the region. Built in 17451746 , it is a cultural heritage associated with the period of Spanish colonization. The Church is dominated (Fig. 2) by two cylindrical towers in its front part and two sacristies in the rear. It is located $35 \mathrm{~km}$ northwest from Nasca City, in a small village $\left(\varphi=14^{\circ} 39^{\prime} 38^{\prime \prime} \mathrm{S}, \lambda=75^{\circ} 11^{\prime} 26^{\prime \prime} \mathrm{W}\right)$. Detailed photogrammetrical documentation was made during expedition in 2008. The churches are not used for religious ceremonies because of the poor technical condition of the building caused by severe earthquakes; the big one in 1940 and some others turned the churches into ruins. Both churches are listed in the World Monuments Fund watching list; this association is engaged in raising funds for repairing major historical monuments. The Jesuit Churches of San José and San Javier are in need of integrated plans for conservation and revitalization in order to ensure their survival for future generations. 3-D documentations, that we made were simplified and placed in Google Earth. The last object is La Ciudad
Perdida de Huayuri (Abandoned town near Huayuri) near Palpa village in a hidden valley. The valley is oriented northeast from the Santa Cruz River, at Huayuri village. The abandoned town is a pre-Columbian town in Peru built in the late medieval period. Its period is dated sometime between the years 1000 and 1450 but it is very hard to say its exact origin and perishing. It is assumed that it was developed during the Huari culture decline and finished with the rise of Inca culture. The town remains are spread in the valley at about 15 hectares area. There are remains of various building walls on the bottom of the valley and on the slopes around. The found buildings are close to each other with a very small space between them which is typical for local human settlement architecture. The building structure of the ruins had only living purposes; objects that could serve some other purposes - for example religious or economical - were not found. At present there is very little information about the "Abandoned town", its inhabitants, and their customs. Most information comes from natives and partly from the previous research undertaken in 1975 and 1984. There was also the project PAHUAY - proyecto archeologico de Huayuri since 2002 to 2005. The 
project was done in cooperation with University of Pittsburgh and Peruvian universities.

\section{Processing and visualisation of objects}

\subsection{Pre-processing of photogrammetric data}

From the photogrammetric point of view, it is necessary to use a calibrated camera for the capturing of image data before creating the 3-D model. In our case the calibration was performed by software PhotoModeler Scanner (PMSC). PMSC is intended for noncontact 3-D measurement. It is based on convergent multi-photo photogrammetry method. This means the 3-D coordinates the points of an object which are computed at least from two convergent, appropriately configured images. PMSC can be used for creating 3-D model, which is possible to export to other software's like CAD systems. The extension of the PMSC can acquire from images point cloud (similarly as laser scanner). In this effort, we used the 3-D documentation of small archaeological funds like funeral ceramic container or other objects. From the created 3-D model, it is possible print replicas on 3-D printer. It is advantageous, because any export of artefacts is prohibited. For a model creating with its real scale, it is necessary to know the object dimensions. There are two approaches: by using control points or by measurement of distances on the object. We used both of these techniques: (a) in the case of archaeological area "Abandoned town" the GNSS GIS instrument was used (our own created base stations in Palpa and Nasca has been used with combination with rover instrument) with a typical accuracy of $60 \mathrm{~cm}$ (b) precise distances measurements on churches ruins. Our acquisition of photogrammetric images and other metric information was simple, because we cannot normally afford more accurate measuring equipment (total station or laser scanners) from financial and administrative reasons in other countries. For this reason, our conducted research was based on existing simple and low cost methods of 3-D documentation in our Laboratory of photogrammetry. All objects were photographed by calibrated digital camera from different stations using convergent photogrammetric technology. Dimensions of objects were determined by measuring tape and laser distance meter. In the case of the both churches, a 3-D model was created from appropriate pictures. Of course, documentation of historical objects is not only a metric survey - other information like historical data, architectonical analysis etc. had to be included to the basic measurement. In developing countries, there is no documentation for most of the lesser-known but still valuable objects and they are of marginal interest (Richter and Teichert, 2008).

\subsection{Evaluation}

\subsubsection{San Jose Church}

Various methods were used for processing and visualisation of objects of interest. We focused on a simple and affordable means. The program Google SketchUp was used for creating the 3-D model of San Jose Church (Fig. 1a); it is the software for creating, modification and 3-D data sharing (Fig. 1b). The present model can be linked through the 3-D gallery of objects in application Google Earth (GE), which is a virtual globe providing maps and geo-information. The application GE allows viewing the Earth on satellite images mosaic with variable resolution. The advantage of software SketchUp is that it works with the GE application. It is very easy to insert a 3-D model into the GE application. SketchUp is simple software for 3-D models and it has no direct functions for object accuracy evaluation. This can be made by comparing of the measured lengths on an object and the same lengths measured on the model. Differences of compared lengths ranged between $0-19 \mathrm{~cm}$ in our project. The average value of the difference $\Delta_{\Phi}=7.8 \mathrm{~cm}$, standard deviation of difference using the formula (1) is $\sigma_{\Delta}=10.0 \mathrm{~cm}$ ( $\Delta$ is difference and $n$ is number of measurement).

$\sigma_{\Delta}=\sqrt{\frac{\sum(\Delta \times \Delta)}{n}}$

\subsubsection{San Javier Church}

The other possibility to create a 3-D model is the appropriate but arbitrary CAD software. MicroStation software was used for creating the model of San Javier Church based on basic photogrammetric processing in PhotoModeler. MicroStation is one of the most popular CAD products, which is used to create 2-D and 3-D drawings. Model accuracy in PhotoModeler software is given by value RMS (residual error). RMS indicates differences between the positions of a point specified by a user and the same point, which the program calculates (the program executes a global adjustment of position of all calculated points). The accuracy of this model reaches approximately 1.5-4.9 pixels. The absolute accuracy depends on pixel size; by our project reaches $1-2 \mathrm{~cm}$. Original photo of San Javier Church is on Fig. 2a. Its 3-D model is in this case without textures, only coloured (Fig. 2b). The visualization is focused on the shape and dimension of the graphical model output for documentation and it is suitable for visible study, for architectural designs or for reconstruction. Our output is a simplified model of the San Javier Church (Fig. 2b). The accuracy of this model has been defined by the lengths. The lengths in the model were measured and compared with the actual lengths on church. Several measures were selected. From these distance differences the standard deviation of twin measurement were calculated (it reaches $4 \mathrm{~cm})$. 

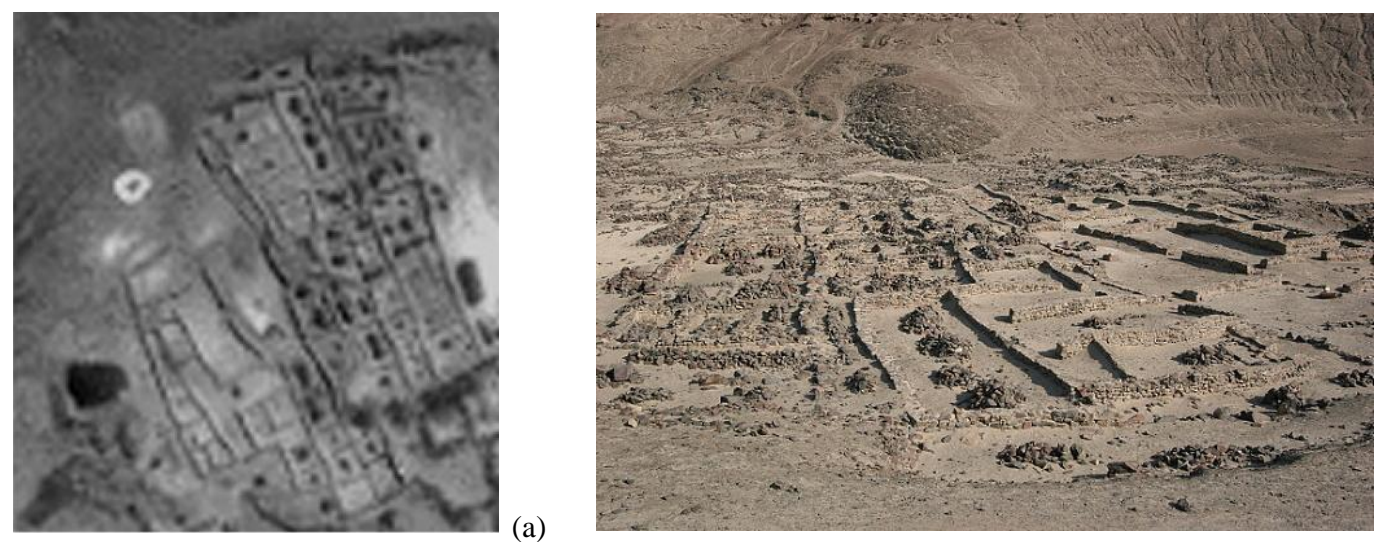

(b)

Fig. 3. "Abandoned town" near Huayuri. GeoEye-1 satellite data (a) after application of filtering. (b) is an example of terrestrial image.

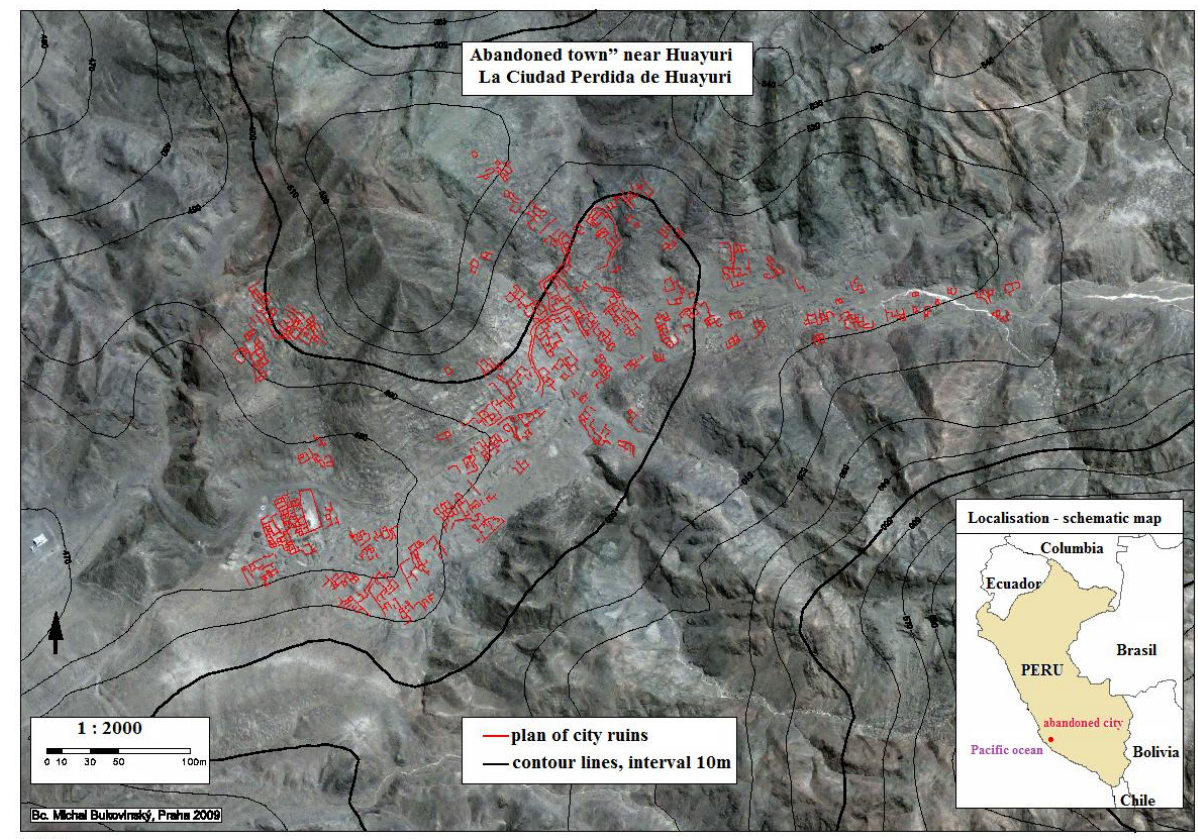

Fig. 4. Thematic map of "Abandoned town” near Huayuri (Bukovinský and Pavelka, 2010).

\subsection{3 "Abandoned town"}

A different approach in case of "Abandoned town" archaeological site was used. It is a very large area for close range photogrammetry. The distances were measured on ruins only for control. Object and control points were measured by GNSS with standard deviation of $55 \mathrm{~cm}$ (base - rover GIS GNSS instrument), which was sufficient for creating of thematic map of this big area (about 15 hectares). The photogrammetric processing combines both terrestrial (Fig. 3b) and satellite images (Guidi et al., 2009). Satellite data was made on demand (new data especially for this project) by the GeoEye-1 satellite with spatial resolution $0.5 \mathrm{~m}$ in panchromatic and $1.64 \mathrm{~m}$ resolution in multispectral imagery. Special procedures for image sharpening and other filtering were used (Fig. 3a). Using PhotoModeler software, a partial model of the abandoned town uncovered by the previous archaeological research has been made. This model was placed into the area with help of the GNSS points measured during the expedition. An important part of the whole area was processed from adjusted and pre-processed satellite data, which has been transformed to geodetic frame by using of measured GNSS points. The final model of the "Abandoned town near Huayuri" was placed into Peruvian coordinate system PSAD56. A newly prepared DEM from Terra/Aster stereo satellite images was used for satellite data processing with resolution of about $15 \mathrm{~m}$, based on GNSS measurement of necessary control points. Good visible objects were vectorised and added as a layer together with contour lines created from DEM to the thematic map (Fig. 4). The results of 
the work are the following: the thematic map the "Abandoned town" near Huayuri in Peru, the 3-D area view in vrml format, video demonstration of flying over the 3-D model, the $\mathrm{kml}$ file for Google Earth (Fig. 4).

It is not possible or very complicated to use other expensive instruments due to financial and administrative reason (Chiabrando et al., 2011). In consequence, calibrated digital cameras and other above mentioned instruments are very effective and they are preferable for small projects (Richter, 2007). Model visualization was made by using animation methods (Pomaska, 2011); VRML browser and 3-D model of San Jose and San Javier churches have been published on the web through Google Earth. The photogrammetric processing was made by PhotoModeler software and the subsequent modelling was made by SketchUp or MicroStation. SketchUp software was used also for textures; there are possibilities to present the model on the internet in 3-D Gallery (Pavelka et al., 2011). By "Abandoned town", the VHR satellite image was used with success (Richter and Teichert, 2008; Pavelka et al., 2010).

The last part of the investigation was experimental dating by radiocarbon analysis of $\mathrm{C}^{14}$. Discovered fireplace remnants in one building were analysed. The result gives two periods (with one sigma range): 1287-1328 AD or 1337-1391 AD (Světlík, 2012). It can be approximately date of the settlement destruction. Of course, it is only one measurement, but it shows possibilities of low cost survey.

\section{Conclusions}

The aim of our study was to show the possibility of easy and non-expensive geometric object documentation and visualisation, which can be used for popularisation and basic reconstruction planning. The 3-D models of the three objects of interest were created through photogrammetric and satellite images. No special instruments were used, only calibrated camera, laser distance meter, tape, software and GNSS instrument. The visualization of the objects of interest can be either a basis for a reconstruction or for simple advertising of the historical objects in areas, where a financial level is not at the accurate targeting geodetic methods or laser scanning. We can conclude that the usage of image data can create outputs of high quality. In some countries documentation and subsequent reconstruction of historical buildings are neglected activities, which can lead to the irreversible loss of such monuments. In addition to the age and a little care taken of historical monuments, there are also threats of war conflicts, nature disasters or vandalism. Recent events in Syria or other countries indicate that this is a real problem. Many foreign projects are focused on these areas, and the Nasca/Peru project is one example of this.

Edited by: K. Tokeshi

Reviewed by: B. Teichert and two anonymous referees

\section{References}

Bukovinsky, M. and Pavelka, K. Using of terrestrial and satellite images for archaeological area modelling, Master Thesis, CTU in Prague, Faculty of Civil Engineering, 2010 (in Czech).

Chiabrando, F., Piatti, D., and Rinaudo, F.: New sensor for cultural heritage metric survey: the ToF cameras, Geoinformatics CTU FCE, 6, 300-307, 2011.

Eisenbeis, H., Lambers, K., Sauerbier, M., and Li, Z.: Photogrammetric documentation of an archaeological site (Palpa, Peru) using an autonomous model helicopter, CIPA XX, International Symposium, Torino, Italy, 2005.

Guidi, G., Remondino, F., Russo, M., Menna, F., Rizzi, A., and Ercoli, S.: A multi-resolution methodology for the 3D modeling of large and complex archaeological areas, International Journal of Architectural Computing, 7(1), 39-55, 2009.

Hanzalová, K. and Čumpelík, Z.: Using of simple photogrammetry for historical object visualization, Master Thesis, CTU in Prague, Faculty of Civil Engineering, 2011 (in Czech).

Kostka, R., and Pavelka, K.: Using of photogrammetry for historical object documentation and visualization, Master Thesis, CTU in Prague, Faculty of Civil Engineering, 2011 (in Czech).

Musílek, L., Čechák, T., Kubelík, M., Pavelka, K., and Pavlík, M.: The Laboratory of Quantitative Methods in Historic Monument Research at the CTU Prague, Radiat. Phys. Chem., 61(3-6), 725727, 2001.

Pavelka, K., Bukovinský, M., Svatušková, J., and Hanzalová, K.: Documentation of the Abadoned Town La Ciudad Perdida In Peru Combining of VHR Satellite and Terrestrial Mesurement, Proceedings of the 30th EARSeL Symposium, Paris, Earsel, 126-137, ISBN 978-3-00-033435-1, 2010.

Pavelka, K., Kostelecký, J., and Klokočník, J.: Google Earth: Inspiration and Instrument for the Study of Ancient Civilizations, Geoinformatics FCE CTU, 6(6), 193-210, 2011.

Pomaska, G.: Proceedings of 23rd CIPA Symposium, Prague, Compiling Stereoscopic 3D Animations from 2D Video Sequences and Virtual Computer Models Exploiting Open Source Software, ISBN 978-80-01-04885-6, 2011.

Richter, Ch.: NascaGIS - An Application for Cultural Heritage Conservation, Dresdner Kartographische Schriften: Nasca Symposium 2006, 115-126, ISSN 1436-0004, 2007.

Richter, Ch. and Teichert, B.: Usability of IKONOS images as a basis of data capture for the NascaGIS, 1st International Workshop on Advances in Remote Sensing for Archaeology and Cultural Heritage Management, Rome/Italy, Aracne, ISBN 978-88-5482030-2, 2008.

Světlík, I.: Radiocarbon dating, Technical report, Nuclear Physics Institute, Prague, 2012. 